\title{
Multi-regime common cyclical features
}

Citation for published version (APA):

Candelon, B., \& Hecq, A. W. (2002). Multi-regime common cyclical features. METEOR, Maastricht University School of Business and Economics. METEOR Research Memorandum No. 050 https://doi.org/10.26481/umamet.2002050

Document status and date:

Published: 01/01/2002

DOI:

10.26481/umamet.2002050

Document Version:

Publisher's PDF, also known as Version of record

\section{Please check the document version of this publication:}

- A submitted manuscript is the version of the article upon submission and before peer-review. There can be important differences between the submitted version and the official published version of record.

People interested in the research are advised to contact the author for the final version of the publication, or visit the DOI to the publisher's website.

- The final author version and the galley proof are versions of the publication after peer review.

- The final published version features the final layout of the paper including the volume, issue and page numbers.

Link to publication

\footnotetext{
General rights rights.

- You may freely distribute the URL identifying the publication in the public portal. please follow below link for the End User Agreement:

www.umlib.nl/taverne-license

Take down policy

If you believe that this document breaches copyright please contact us at:

repository@maastrichtuniversity.nl

providing details and we will investigate your claim.
}

Copyright and moral rights for the publications made accessible in the public portal are retained by the authors and/or other copyright owners and it is a condition of accessing publications that users recognise and abide by the legal requirements associated with these

- Users may download and print one copy of any publication from the public portal for the purpose of private study or research.

- You may not further distribute the material or use it for any profit-making activity or commercial gain

If the publication is distributed under the terms of Article $25 \mathrm{fa}$ of the Dutch Copyright Act, indicated by the "Taverne" license above, 


\title{
Multi-Regime Common Cyclical Features
}

\author{
Bertrand Candelon \\ Alain Hecq * \\ Department of Economics \\ Department of Quantitative Economics \\ University of Maastricht \\ University of Maastricht
}

December $2002^{\dagger}$

\begin{abstract}
In this paper, we consider the hypothesis that particular short-run co-movements indicating that shocks have similar responses might only exist for a particular regime and not for the whole sample. A two-step procedure is set up to test and estimate the multi-regime common cyclical feature. This approach is ullustrated by analyzing the stability of the McCallum's (1994) monetary policy reaction function for Danish data.
\end{abstract}

Keywords: Common Cycles, Markov Switching, Interest Rates

JEL: C22

\footnotetext{
${ }^{*}$ Corresponding author: Alain Hecq, University of Maastricht, Department of Quantitative Economics, P.O. Box 616, 6200 MD Maastricht, The Netherlands. Email: a.hecq@ke.unimaas.nl. Homepage: www.personeel.unimaas.nl/a.hecq.

${ }^{\dagger}$ A previous version of this paper was presented at ESEM 2002 in Venice and at the Common Features meeting in Rio, 2002. The authors gratefully acknowledge financial support from METEOR through the research project "Macroeconomic consequences of financial instabilities". We thank Jean-Pierre Urbain for useful comments and Christian Gengenbach for excellent research assistance. The usual disclaimer applies.
} 


\section{Introduction}

Economic series display many similarities which can be removed by linear combination. Such common features arise when the series exhibit co-movements, i.e. when they are generated by common factors. Examples are common stochastic trends (cointegration), common serial correlation (common cycles), common ARCH, common structural breaks (co-breaking), common seasonality, etc. However, due to the importance of the spurious regression issue, the bulk of the literature has mainly focused on longrun co-movements through cointegration analyses. More recently, some authors have also analyzed the existence of short-run co-movements between stationary time series or between first differences of cointegrated I(1) series, namely the presence of common cyclical features. These will be associated with common business cycles and sometimes interpreted as a condition for economic convergence and an optimal monetary union.

Nevertheless, the presence common cycles can be hard to find over long periods. This paper therefore investigates a less restrictive approach that allows for the existence of multi-regime shortrun co-movements. In the vein of Candelon and Hecq (2000) who propose a recursive analysis to detect breaks in common cyclical feature relationships, our approach permits multiple jumps. In other words, the series have a piecewise serial correlation common feature property such that there exists a stable short-run link between variables within some of the regimes but not necessarily on the full period.

The structure of the paper is as follows. Section 2 presents concepts related to the common cyclical feature literature. Section 3 focuses on estimation procedures. Section 4 reports the outcome of a Monte-Carlo exercise. We investigate in Section 5 the relationship between the variation of the short term interest rate and the term spread in Denmark.

\section{Common Cyclical Features and Collinear Impulse Responses}

According to the common sense a regime represents a period of reasonable stability. We are interested in regimes during which similar shocks have similar impacts. This similarity between the impulse and the response reveals the presence of common transmission mechanisms that result from automatic stabilization mechanisms, the modification in the behavior of economic agents or from the willingness of policy makers to peg the economy.

The strongest form of such relationships is collinear impulse response regimes. In such a situation the system adjusts instantaneously to exogenous shocks and the variables have the Serial Correlation Common Feature property (SCCF hereafter, see Engle and Kozicki, 1993; Vahid and Engle, 1993). To define more precisely SCCF, let us start with $\Phi(L) Y_{t}=\mu+\varepsilon_{t}$, the vector autoregressive model (i.e. a $\operatorname{VAR}(p))$ for a $n$-vector of $\mathrm{I}(1)$ time series $\left\{Y_{t}, t=1, \ldots, T\right\}$, for fixed values of $Y_{-p+1}, \ldots, Y_{0}$ and where 
$\Phi(L) \equiv I_{n}-\sum_{i=1}^{p} \Phi_{i} L^{i} . \varepsilon_{t}$ is $N I D(0, \Omega)$ and $\mu$ is a vector of constant terms. ${ }^{1}$ We further assume that the process $Y_{t}$ is cointegrated of order $(1,1)$ and we rule out $\mathrm{I}(2)$ processes. With $\operatorname{rank}(\Phi(1))=r$, $0<r<n, \Phi(1)$ can be expressed as $\Phi(1)=-\alpha \beta^{\prime}$, with $\alpha$ and $\beta$ both $(n \times r)$ matrices of full column rank $r$. The columns of $\beta$ span the space of cointegrating vectors, and the elements of $\alpha$ are the corresponding adjustment coefficients. Using $\Phi(L) \equiv \Phi(1) L+\Gamma(L) \Delta$ where $\Gamma(L)=I_{n}-\sum_{i=1}^{p-1} \Gamma_{i} L^{i}$, and $\Gamma_{i}=-\sum_{j=i+1}^{p} \Phi_{j}$ for $i=1, \ldots, p-1$ we obtain the vector error-correction model (VECM hereafter, see inter alia Johansen, 1995)

$$
\Delta Y_{t}=\mu+\alpha \beta^{\prime} Y_{t-1}+\sum_{i=1}^{p-1} \Gamma_{i} \Delta Y_{t-i}+\varepsilon_{t}
$$

In (1), the series $\Delta Y_{t}$ have $s$ SCCF relationships if there exists a $n \times s$ full column rank matrix $\delta$ such that $\delta^{\prime}\left(\Delta Y_{t}-\mu\right)=\delta^{\prime} \varepsilon_{t}$ is a $s$-dimensional white noise. ${ }^{2}$ This implies the following restrictions on the VECM parameters in (1): $\left.1^{\circ}\right) \delta^{\prime} \alpha=0$ and $\left.2^{\circ}\right) \delta^{\prime} \Gamma_{i}=0, i=1 \ldots p-1$. Imposing SCCF, the VECM can be written as a factor model $\Delta Y_{t}=\mu+\delta_{\perp} C^{\prime} Z_{t}+\varepsilon_{t}=\mu+\delta_{\perp} F_{t}+\varepsilon_{t}$, with $\delta^{\prime} \delta_{\perp}=0$ and the $(n-s)$ common propagation mechanisms $F_{t}$ are given by the product of a $(n-s) \times(r+n(p-1))$ parameter matrix $C^{\prime}$ and the dynamics in $Z_{t}=\left(Y_{t-1}^{\prime} \beta, \Delta Y_{t-1}^{\prime}, \ldots, \Delta Y_{t-p+1}^{\prime}\right)^{\prime}$.

Beyond the fact that SCCF yields a more parsimonious representation and consequently less coefficients to estimate, the presence of common cyclical features in the dynamics of multivariate time series has some natural implications for their impulse response functions (IRF). Firstly, there could be a decrease in their confidence intervals due to efficiency gains from excluding redundant parameters. Secondly, co-movements imply commonality in IRFs shapes since, by definition, IRFs are collinear for variables exhibiting SCCF (see Vahid and Engle, 1993). ${ }^{3}$ That means that exogenous shocks affecting the linear combination die out in future periods. In order to illustrate this, we simulate two different VAR models of order 1 , indexed by $i=1,2$, for the bivariate stationary process $Y_{t}=\left(y_{1 t}, y_{2 t}\right)^{\prime}$

$$
\left(\begin{array}{l}
y_{1 t} \\
y_{2 t}
\end{array}\right)=\left(\begin{array}{c}
1.15 \\
-0.25
\end{array}\right)+\Phi_{i}\left(\begin{array}{l}
y_{1 t-1} \\
y_{2 t-1}
\end{array}\right)+\left(\begin{array}{l}
\varepsilon_{1 t} \\
\varepsilon_{2 t}
\end{array}\right), \Phi_{1}=\left(\begin{array}{cc}
.7 & -.2 \\
-.2 & .7
\end{array}\right), \Phi_{2}=\left(\begin{array}{cc}
.7 & -.2 \\
-.7 & .2
\end{array}\right)
$$

with the elements of $\Omega, \sigma_{11}=16, \sigma_{22}=25$ and $\sigma_{12}=14$ and where two Data Generating Processes

\footnotetext{
${ }^{1}$ Only an unrestricted intercept has been introduced in the regression. Additional components such as seasonal dummies, outliers, deterministic trends or other exogenous variables can also be considered.

${ }^{2}$ Notice that we could relax the strong white noise assumption underlying SCCF and use less stringent approaches such as the Codependence Cycle (Vahid and Engle, 1997) or the Polynomial Serial Correlation Common Feature (Cubadda and Hecq, 2001).

${ }^{3}$ This is obvious to show because if a matrix $A$ is of reduced rank, powers of $A$ such as $A^{2}, A^{3} \ldots$ used in the computation of IRFs have the same left null space.
} 
$\left(\mathcal{D G} \mathcal{P}_{1}\right.$ and $\left.\mathcal{D} \mathcal{G} \mathcal{P}_{2}\right)$ are determined by different values of autoregressive matrix $\Phi_{i}, i=1,2$. Remark that only the second DGP, i.e. the one with $\Phi_{2}$, implies a SCCF structure with a cofeature vector given by $\delta=(1,1)^{\prime}$. Figure 1 shows a realization for $T=100$ of both processes together with their IRFs. Graphs a) and b) illustrate quite well the difficulty to discriminate graphically between systems with and without the SCCF property. The IRFs have been computed using the Choleski factorization and the shock is $e_{2}=(0,1)^{\prime}$. Figure d) emphasizes that under a SCCF structure, shocks disappear because the sum of the two IRFs is a flat line. These relationships are thus called collinear impulse response regimes.

\section{INSERT FIGURE 1}

However, the presence of SCCF vector could be hidden by some sort of non-linearity in the short run co-movements. In order to emphasize that issue, we consider the Markov Switching VECM (MSVECM hereafter, see Krolzig and Toro, 2000)

$$
\Delta Y_{t}=\mu\left(s_{t}\right)+\alpha\left(s_{t}\right) \beta^{\prime} Y_{t-1}+\sum_{i=1}^{p-1} \Gamma_{i}\left(s_{t}\right) \Delta Y_{t-i}+\varepsilon_{t}
$$

where the unobservable regime variable $s_{t}$ is a Markov chain with $M$ states defined by the transition probabilities $p_{i j}$ and with $\varepsilon_{t} \mid s_{t} \sim N I D\left(0, \Omega\left(s_{t}\right)\right)$. The series in (3) have the Multi-regime Serial Correlation Common Feature property $\left(M S C C F\right.$, hereafter) if there exists a matrix $\delta^{\prime}\left(s_{t}\right)$ with $s_{t} \in(1 \ldots M)$ such that for at least one state, $\delta^{\prime}\left(s_{t}\right)\left(\Delta Y_{t}-\mu\left(s_{t}\right)\right)=\delta^{\prime}\left(s_{t}\right) \varepsilon_{t}$ is an innovation. When $\delta\left(s_{t=1}\right)=\ldots=\delta\left(s_{t=M}\right)=\delta, \mathrm{SCCF}$ is found on the whole period. Notice that the number of collinear impulse response regimes can be smaller than $M$ if only $M^{*}<M$ states have the SCCF property. For instance, it might be possible that due to some rigidities, common cyclical features are observed during booms but not during recessions.

\section{The Estimation Procedure}

Besides the grid search procedure originally proposed by Engle and Kozicki (1993) for common serial correlation and common ARCH, there exist two main methods to test for co-movements and to obtain cofeature vectors. These are the canonical correlation approach and regression techniques based on IV, GIVE or GMM estimators. The second class of estimators has some drawbacks since they rely on the choice of a normalization and become tricky for more than one cofeature relationship but they are easier to carry out in the presence of non-linearities. This is why we only focus on the latter. For the VECM in (1), we denote $W_{t}=\left(\Delta Y_{t-1}^{\prime}, \ldots, \Delta Y_{t-p+1}^{\prime}, Y_{t-1}^{\prime} \hat{\beta}, 1\right)^{\prime}$ the $1+n(p-1)+r$ set of instruments 
composed of the lagged $n$ variables, the error-correction terms and an intercept. ${ }^{4}$ We denote consider the cofeature vector with an intercept by $\tilde{\delta}=\left(1, \theta^{\prime}\right)^{\prime}$. The condition for $\tilde{\delta}$ being a common feature vector for $\left(\Delta y_{1 t}, \Delta X_{t}^{\prime}\right)^{\prime}$ where $\Delta X_{t}=\left(\Delta y_{2 t}, \ldots, \Delta y_{n t}, 1\right)^{\prime}$ can be written as an orthogonality condition $E\left(\left[\Delta y_{1 t}-\Delta X_{t}^{\prime} \theta\right] \otimes W_{t}^{\prime}\right)=0$. The IV estimator using $W_{t}$ is simply the 2SLS such that

$$
\hat{\theta}_{I V}=\left(\Delta \mathbf{X}^{\prime} \mathbf{W}\left(\mathbf{W}^{\prime} \mathbf{W}\right)^{-1} \mathbf{W}^{\prime} \Delta \mathbf{X}\right)^{-1}\left(\Delta \mathbf{X}^{\prime} \mathbf{W}\left(\mathbf{W}^{\prime} \mathbf{W}\right)^{-1} \mathbf{W}^{\prime} \Delta \mathbf{y}_{1}\right)
$$

using the notation for temporal concatenation over $t=1 \ldots T, \mathbf{W}=\left(W_{1}, W_{2}, \ldots W_{T}\right)^{\prime}$. The validity of the orthogonality condition and consequently the presence of a common feature vector is obtained via an overidentification test à la Hansen (see Hamilton, 1994), whose empirical counterpart is

$$
\text { Test }_{1}=\left(\mathbf{u}^{\prime} \tilde{\mathbf{W}}\right)\left(\hat{\sigma}_{u}^{2} \tilde{\mathbf{W}}^{\prime} \tilde{\mathbf{W}}\right)^{-1}\left(\tilde{\mathbf{W}}^{\prime} \mathbf{u}\right)
$$

with $\hat{\sigma}_{u}^{2}$ is the sample variance of the residuals $u_{t}=\Delta y_{1 t}-\Delta X_{t}^{\prime} \hat{\theta}_{I V}$ and where $\tilde{\mathbf{W}}$ is the demeaned $\mathbf{W}$, namely $\tilde{\mathbf{W}}=\mathbf{W}-\mathbf{i}\left(\mathbf{i}^{\prime} \mathbf{i}\right)^{-1} \mathbf{i W}$ (with $\mathbf{i}=(1 \ldots 1)^{\prime}$ ) because we do not want to impose that the cofeature vector also annihilates the constant terms.

Test $_{1}$ assumes homoscedasticity. We also use a robust GMM test statistics that extend the IV estimator by using the White's H.C.S.E. matrix such that (see Hamilton, 1994) ${ }^{5}$

$$
\hat{\theta}_{G M M}=\left(\Delta \mathbf{X}^{\prime} \mathbf{W}\left(\mathbf{W}^{\prime} \mathbf{B} \mathbf{W}\right)^{-1} \mathbf{W}^{\prime} \Delta \mathbf{X}\right)^{-1}\left(\Delta \mathbf{X}^{\prime} \mathbf{W}\left(\mathbf{W}^{\prime} \mathbf{B} \mathbf{W}\right)^{-1} \mathbf{W}^{\prime} \Delta \mathbf{y}_{1}\right),
$$

where the only difference with the usual $\hat{\theta}_{I V}$ estimation is the presence of an additional matrix $\mathbf{B}$ defined as

$$
\mathbf{B}=\left(\begin{array}{cccc}
u_{1}^{2} & 0 & \cdots & 0 \\
0 & u_{2}^{2} & & 0 \\
\vdots & & \ddots & \vdots \\
0 & 0 & \cdots & u_{T}^{2}
\end{array}\right)
$$

with $u_{t}=\Delta y_{1 t}-\Delta X_{t}^{\prime} \hat{\theta}_{I V}, t=1 \ldots T$, the residuals obtained under homoscedasticity using the IV estimation in a first step. We may then form the following new sequence of residuals $u_{t}^{*}=$ $\Delta y_{1 t}-\Delta X_{t}^{\prime} \hat{\theta}_{G M M}$ and use these to compute a new test robust to heteroscedasticity

$$
\text { Test }_{2}=\left(\mathbf{u}^{* \prime} \tilde{\mathbf{W}}\right)\left(\tilde{\mathbf{W}}^{\prime} \mathbf{B} \tilde{\mathbf{W}}\right)^{-1}\left(\tilde{\mathbf{W}}^{\prime} \mathbf{u}^{*}\right)
$$

\footnotetext{
${ }^{4}$ We can choose between first demeaning all the variables in $\Delta Y_{t}$ and in the instruments $W_{t}$ or alternatively to keep an intercept both in the cofeature relationship and in $W_{t}$. These two methods give equivalent cofeature coefficients.

${ }^{5}$ Alternatively, the Newey-West estimator can be used.
} 
Test $_{1}$ and Test 2 asymptotically follow a $\chi_{(v)}^{2}$ distribution under the null of SCCF. The number of degrees of freedom is given by the number of restrictions imposed under the null, i.e. $v=s \times(n(p-$ $1)+r)-s(n-s)$ or $v=n(p-2)+r+1$ with $s=1$. Candelon, Hecq and Verschoor (2002) have illustrated the interest of using Test $_{2}$ with financial data.

With at most one cofeature vector by states, we have under $M S C C F$ the following pseudostructural system

$$
\left\{\begin{aligned}
\left(\Delta y_{1 t}-\Delta X_{t}^{\prime} \theta\left(s_{t}\right)\right) & =\nu_{t} \\
\Delta y_{2 t} & =\mu_{2}\left(s_{t}\right)+\alpha_{2}\left(s_{t}\right) \beta^{\prime} Y_{t-1}+\sum_{i=1}^{p-1} \Gamma_{2, i}\left(s_{t}\right) \Delta Y_{t-i}+\varepsilon_{2, t} \\
& \cdots \\
\Delta y_{n t} & =\mu_{n}\left(s_{t}\right)+\alpha_{n}\left(s_{t}\right) \beta^{\prime} Y_{t-1}+\sum_{i=1}^{p-1} \Gamma_{n, i}\left(s_{t}\right) \Delta Y_{t-i}+\varepsilon_{n, t}
\end{aligned}\right.
$$

with $\nu_{t}=\delta^{\prime}\left(s_{t}\right) \varepsilon_{t}, \delta^{\prime}\left(s_{t}\right)=\left(1, \theta^{\prime}\left(s_{t}\right)\right)^{\prime}$ is the $M S C C F$ vector and where the parameters have been indexed by their line in the VECM. The estimation should provide an estimate of the coefficients in all the states $s_{t}$, the probability of appearance of the regime $M, p_{\left(s_{t}=M\right)}$ at time $t$ (where $\sum_{i=1}^{M} p_{\left(s_{t}=i\right)}=1$ ) and also a probability $p_{i j}$ of transition from a regime $i$ to a state $j$ for the whole sample. Our methodology for testing and estimating multi-regime SCCF consists of a two-step procedure. In the first stage an estimation of the conditional probabilities of being in a particular regime is obtained via the Expectation-Maximization (EM) algorithm (see Dempster, Laird and Rubin, 1977 and Hamilton 1990) with constrained or non constrained variances but with switching the autoregressive parameters. In the second step, we use the transition probabilities obtained in the first step, to build $M$ indicator functions $F_{i}$ for $i=1, \ldots, M$. The function $F_{i}$ takes a 1 in regime $i$ and 0 elsewhere. A test of common feature in regime $i$ is then based on the orthogonality condition $E\left\{F_{i}\left[\left(\Delta y_{1 t}-\Delta X_{t}^{\prime} \theta\right) \otimes W_{t}^{\prime}\right]_{\left(s_{t}=i\right)}\right\}=0$. We must set up a rule to discriminate the regimes. To do so, we use the estimated probabilities of being in a particular state. If these probabilities of being in regime $i$ exceeds a particular threshold $c$, then we consider that regime $i$ prevails. Hamilton (1990) advises to consider $c=0.7$, but we will perform a sensitivity analysis allowing $c=\{0.6,0.7,0.8,0.9\}$.

The behavior of the tests for common features can be affected by the determination of the regimes in the first step. The next section evaluates the small sample performance of our approach through a Monte Carlo study.

\section{Monte-Carlo Simulations}

In order to illustrate the key features of our procedure, we have simulated a two-regime VAR similar to (2) with $\sigma_{11}=\sigma_{22}=1$ and $\sigma_{12}=0.5$ and with $\mu=(0.8,0.8)^{\prime}$. We change the proportion of both regimes and we simulate four different types of DGPs mixing $\mathcal{D G} \mathcal{P}_{1}$ and $\mathcal{D G} \mathcal{P}_{2}$. In the first 
experiment (50-50), $\mathcal{D} \mathcal{G} \mathcal{P}_{1}$ holds for one half the sample whereas $\mathcal{D G} \mathcal{P}_{2}$ is used for the second half. IRFs are collinear in the second regime but not in the first one. In the second experiment (75-25), $\mathcal{D G} \mathcal{P}_{1}$ holds for the first three quarters of the sample and $\mathcal{D G} \mathcal{P}_{2}$ for the last quarter. In the third experiment (25-75), we consider $\mathcal{D G} \mathcal{P}_{1}$ for the first quarter and $\mathcal{D G} \mathcal{P}_{2}$ after. In the last experiment (25-25-50), we allow for two changes in regime: $\mathcal{D G} \mathcal{P}_{1}$ is used for the first and the last quarters and $\mathcal{D G} \mathcal{P}_{2}$ in between. This last case is particularly interesting because it shows the value added of a MS approach over a traditional structural break procedure, namely the possibility to observe multiple changes between regimes. We use 3000 replications and choose a sample size of 200 observations. ${ }^{6}$ Table 1 reports the rejection frequencies for both Test 1 and Test 2 . The first and the second columns of each experiment give the rejection frequencies of the SCCF hypothesis for regime 1 and 2, and thus indicate respectively the power and the size of our test (nominal size is $5 \%$ ).

\section{INSERT TABLE 1}

It turns out that the presence and the location of collinear IRF regimes are correctly detected even when there are two changes (experiment 4). The first step of the procedure has only a small impact on the overall outcome of the tests. No size distortions is observed when both regimes contain half of the sample. If we decrease the number of observations for one regime, the latter becomes more difficult to estimate accurately and the empirical size increases even though the number of observations is larger (like in the 25-75 case). The statistic Test 2 behaves slightly better than Test ${ }_{1}$. The link between the rejection frequencies and the threshold $c$ is also in line with our expectations, as we notice that the empirical size gets closer to $5 \%$ as $c$ increases. The power is high and increases with the sample size.

However, there may exist a border effect resulting from the inclusion of points coming from another regime when performing the test statistic. To illustrate this we have done the same experiments but we take subsamples by dropping $1 \%$ of the sample size both on the right and the left hand sides of each estimated regimes. We observe that although for $T=200$, only two points are skipped from each sides, a decrease of the size distortions is noticeable. For the four experiments with Test $t_{1}$ and $c=0.9$, the rejection frequencies becomes respectively $6.77,7.85,7.65$ and 7.34 instead of $6.87,10.33$, 8.93 and 8.38 .

Finally, we have also performed the simulations for the unconstrained variance case and we recommend in this case to use Test 2 with $c=0.9$. With this specification the size of the test (without dropping border points) is $7.82,8.32$ and 8.20 for the first three cases.

\footnotetext{
${ }^{6}$ Gauss routines are available upon request. Initial conditions for regime 1 correspond to the estimations obtained by OLS on the whole sample. For regime 2, they are set up to $-0.5^{*}$ OLS estimations. 152 points are used to initialize the process.
} 


\section{Empirical Analysis}

We illustrate our analysis using the monetary policy reaction model developed by McCallum (1994)

$$
\Delta r_{t} \equiv r_{t}-r_{t-1}=\lambda\left(R_{t}-r_{t}\right)+\epsilon_{t}
$$

The rule is based on the observation that central banks adjust the short term interest rate $r_{t}$ in function of the term spread $R_{t}-r_{t}$. The policy parameter is $\lambda \geq 0$ and $\epsilon_{t}$ is an error term representing exogenous short rate shocks, namely other components of the policy behavior. Even though monetary authorities generally use a wider range of policy indicators than the spread, the correlation between the spread and other indicators such as the real economic growth and/or inflation expectations is high. Consequently, central banks increase $r_{t}$ when widening spread signals higher expected future inflation and correspondingly higher short rates. Of course $\epsilon_{t}$ does not need to be white noise but it measures the speed of adjustment of the reaction function and the potential presence of omitted policy indicators. ${ }^{7}$

We use Danish 1- and 3 months interest rates, sampled at monthly frequency and covering the period January 1976, December 1991. These series are taken from Engsted and Nyholm (2000) who have analyzed the change in the monetary policy that occurred between 1983 and August 1985. Before that period the Danish monetary policy could roughly be characterized by a quantitative control over the money supply through the adjustment of the short term interest rate. The fixed exchange rate regime introduced in the beginning of 1983 and the official interest rate targeting in August 1985, have reduced the scope of that monetary policy.

Figure 2 presents the conditional probabilities of being in regime 1 with a $\operatorname{VAR}(2)$. It is similar to Figure 3 in Engsted and Nyholm (2000) for the VAR(1) case. We detect a change in regime in 1984:4, namely a few months later than Engsted and Nyholm (2000), and it turns out that regime 1 covers the period 1984:5-1991:12 and regime 2 spans 1976:4-1984:3. Table 2 reports the outcome of the common feature tests within a $\operatorname{VAR}(1)$ and a $\operatorname{VAR}(2)$. It also includes the estimation of the cofeature coefficient in $\Delta r_{t}=\hat{\lambda}$ spread $_{t}$ for the robust GMM (Test $\left.t_{2}\right)$ with switching variances. Test statistics have respectively 1 and 3 degrees of freedom under the null and consequently we cannot reject the presence of a SCCF relationship in both regimes. However, the policy parameter has dramatically decreased in the second part of the sample showing that stable exchange rate objective yielded to the loss of the monetary instrument. Such a result confirms the conclusions in Juselius (1998) for money demand.

\footnotetext{
${ }^{7}$ Equation (4) is one of the equation of a model that tries to reconcile the expectation hypothesis of the term structure of interest rates with empirical findings and it has been used by Hsu and Kugler (1997) and Kugler (2000) for instance.
} 


\section{INSERT TABLE 2 AND FIGURE 2}

\section{Conclusion}

In this paper, we have proposed a new approach to detect multi-regime common cyclical features. This method constitutes a simple two-step procedure, which first estimates the regimes, and then tests for the presence of common features on these states. This work can be considered in the line of Diebold and Rudebush's (1994) analysis for dynamic factors models with regime switching. We applied this test to analyze a monetary reaction function à la McCallum (1994) for Danish data. Similarly to Engsted and Nyholm (2000), two distinctive states are detected. The coefficients of the 2-regime SCCF reveal that the monetary policy strength decreased after April 1984. The institutional changes which occurred in Denmark in 1983 (lifting of capital restrictions and the adoption in March 1983 of a less flexible European Exchange Rate Mechanism) explain the changes in the conduct of monetary policy.

\section{References}

[1] Candelon, B. And A. Hecq (2000), Stability of Okun's Law in a Codependent System, Applied Economic Letters, 7, 687-693.

[2] Candelon, B., Hecq, A. and W. Verschoor (2002), Measuring Common Cyclical Features During Financial Turmoil, Maastricht University, Research Memorandum, RM/02/028.

[3] Cubadda, G. and A. Hecq (2001), On Non-Contemporaneous Short-Run Comovements, Economics Letters, 73, 389-397.

[4] Dempster, A.P., Laird, N.M. and D.B. Rubin (1977), Maximum Likelihood Estimation from Incomplete Data via EM Algorithm, Journal of the Royal Statistical Society, 39, Series B, $1-38$.

[5] Diebold, F.X. And G.D. Rudebusch (1994), Measuring Business Cycles: A Modern Perspective, NBER Working Paper Series \# 4643.

[6] Engle, R. F. And S. Kozicki (1993), Testing for Common Features (with comments), Journal of Business and Economic Statistics, 11, 369-395.

[7] Engsted, T. and K. Nyholm (2000), Regime Shifts in the Danish Term Structure of Interest Rates, Empirical Economics, 25, 1-13. 
[8] Hamilton, J.D. (1990), Analysis of Time Series subject to Change in Regime, Journal of Econometrics, 45, 39-70.

[9] Hamilton, J.D. (1994), Time Series Analysis, Princeton University Press.

[10] Hsu, C. And P. Kugler (1997), The Revival of the Expectations Hypothesis of the US Term Structure of Interest Rates, Economics Letters, 115-120.

[11] Johansen, S. (1995), Likelihood-Based Inference in Cointegrated Vector Autoregressive Models, Oxford University Press.

[12] Juselius, K. (1998), Changing Monetary Transmission Mechanisms Within EU, Empirical Economics, 3, 455-481.

[13] Kugler, P. (2000), The Expectations Hypothesis of the Term Structure of Interest Rates, Open Interest Rate Parity and Central Bank Policy Reaction, Economics Letters, 209-214.

[14] Krolzig, H.M and J. Toro (2000), A New Approach to the Analysis of Business Cycle Transitions in a Model of Output and Employment, Mimeo Oxford University, Nuffield college.

[15] McCallum, B. (1994), Monetary Policy and the Term Structure of Interest Rates, NBER Working Paper 4938.

[16] Vahid, F. and R. F. Engle (1993), Common Trends and Common Cycles, Journal of Applied Econometrics, 8, 341-360.

[17] Vahid, F. And R. F. Engle (1997), Codependent Cycles, Journal of Econometrics, 80, 199-221. 
Figure 1 - VAR(1) with and without common features

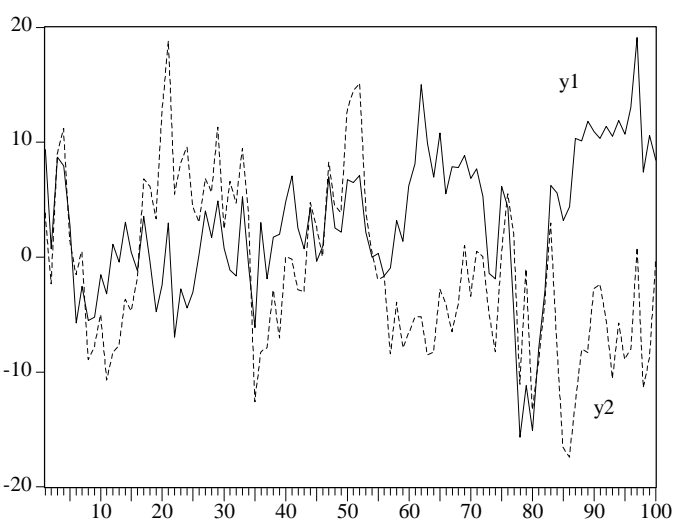

a) Series without common features

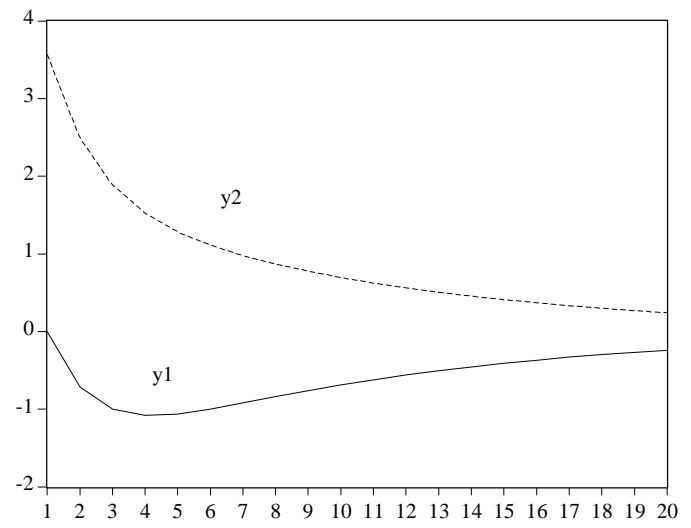

c) $\mathcal{D G} \mathcal{P}_{1}$, response to $e_{2}$ shock

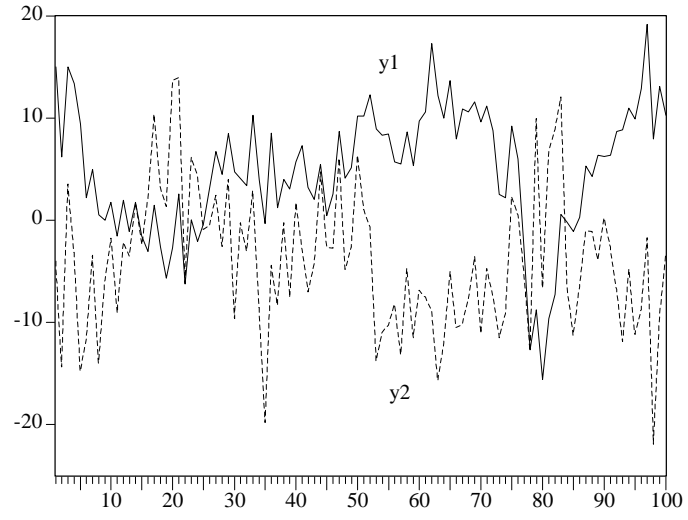

b) Series with common features

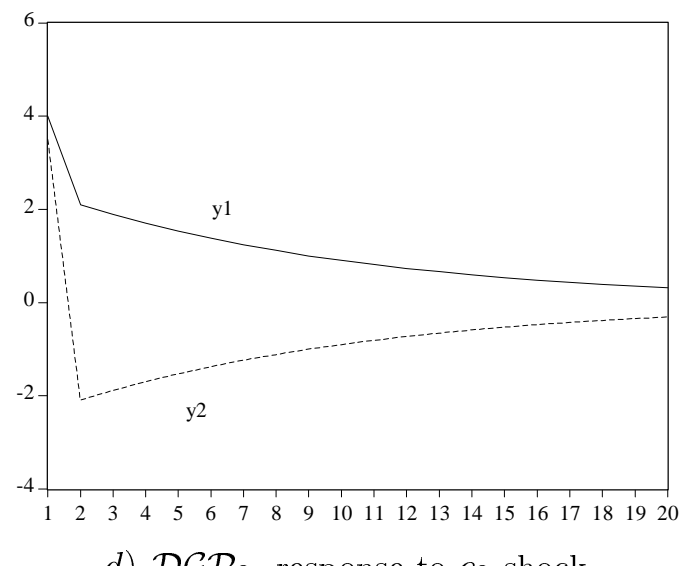

d) $\mathcal{D} \mathcal{G} \mathcal{P}_{2}$, response to $e_{2}$ shock

Figure 2 - Conditional probability of being in regime 1

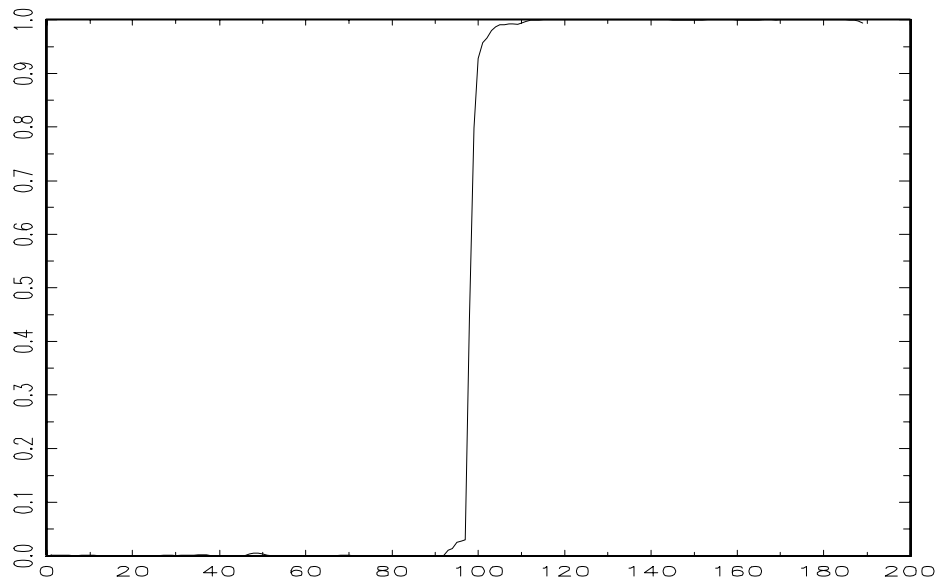


Table 1. Rejection frequencies of the SCCF hypothesis $\left(T=200 ; \sigma_{1}=\sigma_{2}\right)$

\begin{tabular}{|cc|cc|cc|cc|cc|}
\hline \hline & & \multicolumn{2}{|c|}{$(50 / 50)$} & & \multicolumn{2}{c|}{$(75 / 25)$} & & $(25 / 75)$ & \\
& & Power & Size & Power & Size & Power & Size & Power & Size \\
\hline Test $_{1}$ & $c=0.6$ & 97.93 & 7.44 & 98.27 & 12.87 & 80.85 & 9.84 & 97.78 & 9.42 \\
& $c=0.7$ & 97.69 & 7.37 & 98.00 & 12.19 & 80.41 & 9.60 & 97.75 & 9.21 \\
& $c=0.8$ & 97.73 & 7.24 & 97.48 & 11.67 & 79.81 & 9.30 & 97.42 & 8.98 \\
& $c=0.9$ & 97.49 & 6.87 & 96.34 & 10.33 & 78.73 & 8.93 & 96.71 & 8.38 \\
\hline Test $_{2}$ & $c=0.6$ & 97.99 & 7.00 & 98.24 & 11.50 & 79.54 & 9.10 & 97.65 & 9.25 \\
& $c=0.7$ & 97.86 & 6.97 & 97.86 & 10.60 & 78.60 & 8.83 & 97.48 & 8.78 \\
& $c=0.8$ & 97.76 & 6.84 & 97.48 & 9.53 & 78.19 & 8.63 & 97.15 & 8.41 \\
& $c=0.9$ & 97.53 & 6.97 & 96.28 & 8.74 & 76.75 & 8.06 & 96.68 & 8.14 \\
\hline \hline
\end{tabular}

Table 2: Test statistics and cofeature coefficient for each regimes

\begin{tabular}{|cc|cc|cc|}
\hline \hline $\operatorname{VAR}(p)$ & & $p=1$ & & $p=2$ & \\
& & Regime 1 & Regime 2 & Regime 1 & Regime 2 \\
\hline \multirow{2}{*}{ Test $_{2}$} & $c=0.6$ & 2.32 & 0.07 & 3.69 & 0.42 \\
& $c=0.9$ & 2.35 & 0.07 & 3.76 & 0.42 \\
\hline$\hat{\lambda}$ & $c=0.6$ & 0.27 & 2.48 & 0.58 & 2.66 \\
& $c=0.9$ & 0.24 & 2.48 & 0.52 & 2.66 \\
\hline \hline
\end{tabular}

